\title{
First Use of Thermal Stabilized Hyaluronic Acid Injection in One-Year Follow-Up Patients with Genitourinary Syndrome
}

This article was published in the following Dove Press journal: Medical Devices: Evidence and Research

\author{
Elisabetta Garavaglia (D) \\ Cinzia Sala ${ }^{2}$ \\ Manuela Busato' \\ Gilberto Bellia $\mathbb{D D}^{3}$ \\ Nadia Tamburlin' \\ Alberto Massirone' \\ 'Agorà, Italian Scientific Society of \\ Aesthetic Medicine, Milan, Italy; ${ }^{2}$ Private \\ Practice, Milan, Italy; ${ }^{3}$ Medical Affair, IBSA \\ Farmaceutici, Italia Srl, Lodi, Italy
}

Objective: Evaluation of the impact of hyaluronan hybrid cooperative complex (HCC) injections in premenopausal and postmenopausal Italian women affected by vulvar-vaginal atrophy (VVA), one of the symptoms of genitourinary syndrome (GS), on self-reported quality-of-life, vaginal symptoms, and sexual activity, as well as treatment side-effects.

Methods: We surveyed a sample of 26 women affected by VVA with follow-up at 6 and 12 months. Deep intradermal injections of HCC were delivered at 1-month intervals. Evaluation of the treatment impacting the VVA patients was assessed by three international validated questionnaires (Visual Analogic Scale, VAS; health-related quality-of-life test, SF12; Female Sexual Function Index, FSFI). The statistically significant differences between pre- and aftertreatment responses have been assessed by Wilcoxon signed-rank test and repeated measures ANOVA test.

Results: At 6-12-month follow-up, general quality-of-life (SF12) did not show any significant improvement. On the contrary, VVA patients showed significant improvements of genital symptoms (VAS) and sexual function (FSFI). Global FSFI score increased by 58\% and evidenced important satisfaction $(P \leq 0.05)$.

Conclusion: Vestibular HCC injection is an office, safe, fast, not expensive, and reproducible procedure effective in vulvar-vaginal atrophy. This study can be used as a pilot for future trials.

Keywords: hyaluronic acid, bio-stimulation, vulvovaginal atrophy, genito-urinary syndrome of menopause, hyaluronic acids injection, menopause, hyaluronan hybrid cooperative complexes

\section{Introduction}

Genitourinary syndrome (GS), ${ }^{1}$ previously called vulvovaginal atrophy (VVA), is a common condition affecting up to the $90 \%$ of post-menopausal women, ${ }^{2}$ associated with physical changes of the vulva, vagina, and lower urinary tract. $^{3}$ Pain, dyspareunia, burning, itching, and dryness, mainly at the posterior vaginal vestibule, are the main conditions reported by patients, responsible for the sexual impaired function (Figure 1). Decreasing levels of sex steroids in postmenopausal time are likely responsible of the co-occurring urinary problems, such as urgency, urge incontinence, dysuria, and infections. Other symptoms associated with GS of menopause are moderate-to-severe vestibulitis, vaginism, and hypertonic pelvic muscles. ${ }^{4,5}$ The GS might also occur in premenopausal state under conditions of hypoestrogenism: post-partum period, after oophorectomy, radiotherapy,
Correspondence: Elisabetta Garavaglia Agorà, Italian Scientific Society of Aesthetic Medicine, Piazza Caiazzo I, Milan 20I24, Italy

Tel +39 3382731072

Email Garavaglia.Elisabetta@hsr.it
Medical Devices: Evidence and Research 2020:13 399-4l0 


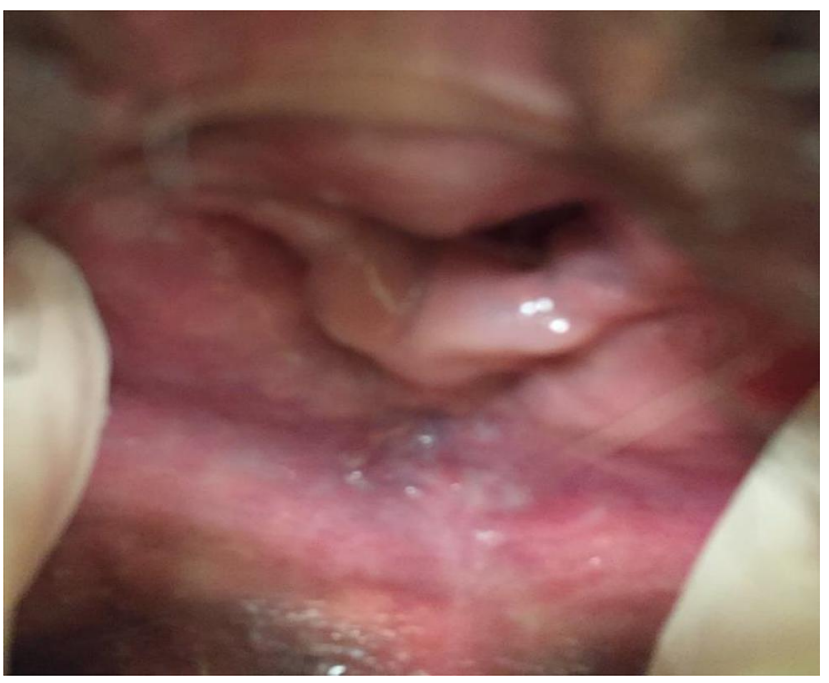

Figure I A typical vulvovaginal atrophy mainly localized in the posterior vaginal vestibule

chemotherapy or during pill and drugs intake, as well as after recurrent infections, and affects more than $20 \%$ of premenopausal women. $^{2}$

Although diagnosis of GS is clinic, a few published histological examinations have reported several dermoepidermal alterations in some postmenopausal women, evidencing quiescent fibroblasts, reduced and dehydrated extra-cellular matrix, inversion of collagen ratio I-III with altered trabecular architecture, reduced elasticity, vascularization, as well as thickness of the vaginal lining ${ }^{6,7}$.

Several systemic and local treatments have been proposed, such as estrogen and estrogen receptor modulators (ie, ospemifene) $)^{8,9}$, intravaginal application of dehydroepiandrosterone (DHEA; i.e, prasterone), as well as local moisturizers and lubricants. Depending of the severity of GS, these treatments showed different efficacy, outcome, and side-effects, and none of them was completely successful in treating the disease. ${ }^{10-12}$

Recently, GS has also been treated by carbon dioxide $\left(\mathrm{CO}_{2}\right)$, erbium laser, or monopolar radiofrequency, with promising results, ${ }^{13,14}$ but also complications ${ }^{15}$ that have induced the Food and Drug Administration (FDA) to prohibit their usage in this disease. ${ }^{16}$ In addition, energy-based devices are expansive and require a long training period.

Hyaluronic acid (HA) is involved in important biological functions in most connective tissues, such as regulation of cell adhesion and motility, cell differentiation, proliferation, and tissue repair. ${ }^{17}$ Thanks to these properties, HA is the principal compound of esthetic treatments. The large stereometric size does not allow HA to penetrate the skin barrier. Therefore, it is introduced in the dermal layer through injections for different purposes. The crosslinked form (filler) is used for hydrodynamic volume replacement of the extracellular matrix to reduce the clinical effects of aging and volumize the skin. ${ }^{18}$ The free noncross-linked form attracts water and bio-stimulates dermic tissue, activating the fibroblast cell, ${ }^{19-25}$ keratinocytes, ${ }^{26,27}$ and realizing an antioxidant effect. ${ }^{28}$

Mostly studied as a treatment for facial damage and aging, the pharmacological properties of HA can be applied to other conditions such as vulvar-vaginal atrophy. Although different products are already available over the counter for this purpose, the biological evidence is scarce $^{29,30}$.

To the best of our knowledge, we present the first experience that applies hyaluronan hybrid cooperative complexes (HCC) alone injections in the vaginal-vestibular area in order to bio-stimulate the atrophic tissue in a sample of pre- and postmenopausal women showing moderate-tosevere symptoms that can be associated to GS. We aim to evaluate the self-rated health status of the patients, the safety of the treatment, and the effect of the treatment on the symptoms and general health reported by the patients.

\section{Methods}

\section{Subjects Selection}

Twenty-nine pre-menopausal and post-menopausal Caucasian women predominantly affected by vulvarvaginal atrophy and/or GS were prospectively enrolled in 2018-2020. Since diagnosis is clinical, the examination was performed by two gynecologists. Pain, dyspareunia, burning, itching, and dryness, mainly at the posterior vaginal vestibule, were the main conditions reported by patients, which were responsible for the sexual impaired function and variously associated to urinary problems, such as urgency, urge incontinence, dysuria, and infections. At gynecological exam, all patients presented objective vaginal vestibular alterations, above all at the posterior introitus: dried, pale, inelastic, sclero-atrophic, thin skin, showing vascular alteration. In some patients several painful ulcers were observed too.

Accordingly to Italian law, this case series was exempt from ethic committee approval because the study product has been used according to the instructions given in the package leaflet. This case series was conducted according to the ethics of the Declaration of Helsinki. The information and data were generated, recorded, documented, and 
processed in accordance with a specific procedure, based on The International Council for Harmonization of Technical Requirements for Pharmaceuticals for Human Use (ICH) Good Clinical Practice (GCP). All the participants signed an informed consent form at the time of the enrollment in order to collect the clinical data.

Exclusion criteria included age $<18$ years, pregnancy, connective tissue, and collagen vascular diseases, concomitant treatments with estrogen, microablation with any laser device in the 12 months prior to the study start, or $\mathrm{CO}_{2}$ laser, previous genital filler treatment, the presence of genital herpes, or other genital infections. Clinical and significant skin condition on the area to be treated (eg, active eczema, dermatitis, psoriasis, etc.). Drug allergy.

\section{Treatment Protocol}

The patients were treated with deep intradermal injections of one prefilled syringe of $2 \mathrm{~mL}$ of a thermal stabilized hyaluronan hybrid cooperative complex (HCC) $(32 \mathrm{mg} / \mathrm{mL}$ of HA of $1,100-1,400 \mathrm{kD}$ MW plus $32 \mathrm{mg} / \mathrm{mL}$ of $\mathrm{HA}$ of $80-100$ kD) (IBSA Farmaceutici Italia Srl) in two treatments at 1-month intervals each by two gynecological clinics, according to the scheme proposed for that product.

Each treatment was administered at the gynecologist's office following the same protocol: the patient locally applied an anesthetic cream herself (2.5\% lidocaine plus $2.5 \%$ prilocaine) at the vaginal-vestibular area 30 minutes before the procedure. The area was locally disinfected using $0.1 \%$ of benzoxonium chloride. Then a local anesthesia was performed with $2-3 \mathrm{~mL}$ of Lidocaine Hydrochloride $2 \% \mathrm{w} / \mathrm{v}$ Solution for Injection, using a 30 Gauge needle, $13 \mathrm{~mm}$ long. After the first anesthetic welt, the HCC injection is executed in the previous anesthetic area in a circus way along the whole vulvar vestibule. Six deep intradermal injections of $2 \mathrm{~mL}$ of $\mathrm{HA}$ along the vulvar vestibule are administrated according to a linear retrograde technique: two at the anterior $(0.3 \mathrm{~mL})$ and posterior entries $(0.5 \mathrm{~mL})$ and two at the lateral sides, $0.3 \mathrm{~mL}$ each, using $29 \mathrm{G} 13 \mathrm{~mm}$ long needles. A local manual massage was conducted and was suggested to also be performed over the next 3 days. The subsequent treatment was executed after 1 month when required by the patient.

\section{Survey}

Each patient has been surveyed with demographic and anamnestic questions before the first treatment together with three internationally validated questionnaires:
1. The first questionnaire includes information on participants pathologies and on their family medical history that can influence their general and sexual life.

2. The Visual Analog Scale test (VAS) ${ }^{31}$ is based on the most common pain scale that is used for quantitation of different disease-related pain. Pain level is associated with a numeric value (1-10) where discrete intervals are indicated $(1-3=$ low; $4-6=$ mild; $7-10=$ severe) for each of the following types of pain: vaginal burning, itching, dryness, pain during penetration, painful urination.

3. The health-related quality-of-life test $(\mathrm{SF} 12)^{32}$ is a questionnaire reporting the 12 questions contained in the 12-item Short Form Health Survey (SF-12) which has been designed to get a measure of healthrelated quality-of-life. It assesses both the physical and mental domains, that are aggregated, weighted and standardized. The highest score indicates the healthiest status.

4. The third survey is the Female Sexual Function Index (FSFI) ${ }^{33}$ to assess the quality of sexual life in five domains: degree of desire, arousal, lubrification, orgasm, and pain. The highest score indicates the healthiest status.

Four investigation periods have been performed during the study: a basal gynecological visit, preceded by the administration of the three surveys, a registry schedule and a clinical assessment, during the first injection (T0), a second gynecological exam, preceded by the three investigation surveys after 4 weeks, during the second treatment (T1), 6 (T6), 12 (T12) months after the first injection procedure through the three questionnaires, with a declaration of final patient satisfaction.

Data are collected using online questionnaires designed ad hoc for this study. The LimeSurvey Professional has been chosen as our online survey service (https://www. limesurvey.org/) which is compliant with European GDPR rules. Surveys are collected anonymously using tokens, and the results are downloaded and stored on a dedicated and password protected HD. Survey results are removed from LimeSurvey server once completed.

Follow-up questionnaires have been administrated to each patient before the second treatment (after 1 month), to $\mathrm{N}=24$ patient after 6 months and to $\mathrm{N}=11$ patients after 12 months. No dropouts have been reported. This study is ongoing and that explains the different patients number at each time of investigation. 
We also evaluated participants' tolerance to the procedure, potential side-effects or claims, and eventual third treatment.

\section{Statistical Analysis}

According to each international validated questionnaire guidelines, patient-specific VAS, SF-12, and FSFI scores have been assessed at each timepoint: pre-treatment (T0), pre-second treatment (T1), after 6 months (T6), and after 12 months (T12) using ad hoc scripts in R 3.3.3 environment (The R Foundation for Statistical Computing). For each final score, the statistically significant differences among the median scores across the timepoints have been estimated using a Wilcoxon signed-rank test $(P<0.05)$. The statistical tests as well as the boxplot and the line plots have been performed using R 3.3.3 environment (Wilcox and ggplot2 package). The administration by two gynecologists has been analyzed as a confounding factor.

\section{Results}

Twenty-nine Italian women of Caucasian origin showing prevalent vulvar-vaginal atrophy in GSM were enrolled. Table 1 reports the demographic characteristics and anamnesis for the 26 recruited patients. Participants' ages ranged from $24-61$ (mean $=45.5 \pm 11.6$ years; median $=47$ years) including $41 \%$ at menopausal age ( 7 years before the treatment on average). Fifty-two percent of participants were primiparous or multiparous $(100 \%$ vaginal delivery). Eleven out of 29 women did not have sexual intercourse with the partner, and $36 \%$ had sexual intercourse after the first and/or the second treatment. The enrolled women were not affected by other diseases. Mean time of the procedure was 20 minutes. During or after the treatments, no pain was reported by the patients, and no complications or side-effects were observed. After the first treatment, 26 out of 29 enrolled women were surveyed at timepoints T1 and T6 and 11 out of 29 at time point T12. Only one patient required a third treatment, 10 months after the first. The administration by two gynecologists, analyzed as a confounding factor, did not show any significant effect. The clinical results were captured in pictures (Figure 2).

\section{Visual Analogic Scale (VAS)}

The gynecological symptomatology before and after treatments has been surveyed in 26 women. High scores
Table I Demographic Characteristics and Anamnesis for $\mathrm{N}=29$ Recruited Patients

\begin{tabular}{|c|c|c|}
\hline Characteristics & $\mathbf{N}$ & $\%$ \\
\hline \multicolumn{3}{|l|}{ Medical practice } \\
\hline Lombardia & 19 & 65,5 \\
\hline Veneto & 10 & 34,5 \\
\hline Treated patients ( 2 treatments) & 29 & 100,0 \\
\hline $\begin{array}{l}\text { Treated patients (additional } \\
\text { treatment after } 6 \text { months) }\end{array}$ & 1 & 3,4 \\
\hline \multicolumn{3}{|l|}{ Marital status } \\
\hline $\begin{array}{l}\text { Married/Domestic partner (>10 } \\
\text { years) }\end{array}$ & 12 & 41,4 \\
\hline $\begin{array}{l}\text { Married/Domestic partner }(\leq 10 \\
\text { years) }\end{array}$ & 8 & 27,6 \\
\hline Partner (not domestic) & 2 & 6,9 \\
\hline Divorced & 2 & 6,9 \\
\hline Single & 4 & 13,8 \\
\hline Unknown & 1 & 3,4 \\
\hline \multicolumn{3}{|l|}{ Educational attainment } \\
\hline $\begin{array}{l}\text { Less than high school diploma (8 } \\
\text { years) }\end{array}$ & 3 & 10,3 \\
\hline High school diploma (13 years) & 16 & 55,2 \\
\hline Graduate & 8 & 27,6 \\
\hline Postgraduate & 2 & 6,9 \\
\hline \multicolumn{3}{|l|}{ Occupation } \\
\hline Self-employed & 4 & 13,8 \\
\hline Employee & 12 & $4 I, 4$ \\
\hline Teacher & 4 & 13,8 \\
\hline Researcher/Laboratory technician & 3 & 10,3 \\
\hline Manager & 2 & 6,9 \\
\hline Student & 1 & 3,4 \\
\hline Unemployed & 1 & 3,4 \\
\hline Housewife & 1 & 3,4 \\
\hline Retired & 1 & 3,4 \\
\hline \multicolumn{3}{|l|}{ Religious belief } \\
\hline Churchgoer & 13 & 44,8 \\
\hline Not churchgoer & 10 & 34,5 \\
\hline Unknown & 6 & 20,7 \\
\hline \multicolumn{3}{|l|}{ Offspring } \\
\hline Primiparous & 6 & 20,7 \\
\hline Multiparous (up to 2) & 9 & 31,0 \\
\hline Nulliparous & 13 & 44,8 \\
\hline Unknown & 1 & 3,4 \\
\hline \multicolumn{3}{|l|}{ Delivery type } \\
\hline Natural & 15 & 100,0 \\
\hline \multicolumn{3}{|l|}{ Caregiver (parents) } \\
\hline Yes & 2 & 6,9 \\
\hline No & 25 & 86,2 \\
\hline Unknown & 2 & 6,9 \\
\hline
\end{tabular}

(Continued) 
Table I (Continued).

\begin{tabular}{|c|c|c|}
\hline Characteristics & $\mathbf{N}$ & $\%$ \\
\hline \multicolumn{3}{|l|}{ Surgical intervention } \\
\hline Yes & 2 & 6,9 \\
\hline No & 27 & 93,1 \\
\hline \multicolumn{3}{|l|}{ Hormonal therapy } \\
\hline Yes & I & 3,4 \\
\hline No & 28 & 96,6 \\
\hline \multicolumn{3}{|c|}{ Menopause status at treatment } \\
\hline Before menopause & 15 & $5 \mathrm{I}, 7$ \\
\hline After menopause & 14 & 48,3 \\
\hline Age at treatment (years) & Range(years) & Mean (SD) \\
\hline Before menopause & $24-48$ & $35.9(7.2)$ \\
\hline After menopause & $53-61$ & $55.9(3.8)$ \\
\hline $\begin{array}{l}\text { Time between menopause and } \\
\text { treatment(years) }\end{array}$ & $1-13$ & $6.7(3.8)$ \\
\hline
\end{tabular}

indicate poor health status. Dyspareunia at sexual entry was the most complained upset and HA injections were demonstrated as efficacious for the all referred gynecological symptoms (Table 2).

When considering the total VAS score calculated using all the answers at each timepoint (Figure 3), the median VAS score significantly decreased from 23.0 (mean $=22.6$; $\mathrm{SD}=14.4)$ pre-treatment to $5.0($ mean $=13.0 ; \mathrm{SD}=10.8)$ at 6 months after the treatment $(P=0.038)$ and to 5.0 (mean=11.2; $\mathrm{SD}=9.2$ ) at 12 months after the treatment $(P=0.015)$.

\section{Health-Related Quality-of-Life Test (SFI2)}

The weighted standardized physical scores (PCS-12) showed an improving nominally significant trend across the timepoints T0-T12 (Figure 4). The positive trend observed for the physical quality-of-life with slightly increasing median score from 52.6 at T0, 52.7 at T1, 54.0 at $\mathrm{T} 6$, and 55.6 at $\mathrm{T} 12$ and the borderline significant differences between $\mathrm{T} 0$ and $\mathrm{T} 12$ need to be further investigated in a larger sample size. The mental scores (MCS-12) showed a positive not significant improvement from T0 (median=50.0) to $\mathrm{T} 1$ (median=54.7), but no positive trend has been detected after the second treatment (Figure 5).

When considering the whole group of 11 patients with PCS12 and MCS- 12 scores at T0, T1, T6, and T12, the sum of the two indices showed an increasing trend from SF-12: 1,084 at T0, 1,105 at $\mathrm{T} 1,1,113$ at $\mathrm{T} 6$, and 1,115 at $\mathrm{T} 12$ (Figure 6).

\section{Female Sexual Function Index (FSFI)}

FSFI score, concerning the quality of patients' sexual lives, revealed significant improvement at each time of the survey (Figure 7). The median FSFI score was 20.8 (mean=22.2; SD=7.6) before the first treatment. One month after the first treatment and before the second one, the median FSFI score showed a significant increase to 28.3 , representing a $36 \%$ improvement



Figure 2 (A) A painful episiotomic scar in a vulvovaginal atrophy before the first treatment (B) the scar disappearance after the first treatment. 
Table 2 Visual Analogic Scale for N=26 Patients ${ }^{\$}$ at Each Timepoint

\begin{tabular}{|c|c|c|c|}
\hline Categories & $\mathbf{N}$ & Mean (SD) & Median \\
\hline \multicolumn{4}{|l|}{ Vaginal burning } \\
\hline T0 & 26 & $3.8(3.5)$ & 4,0 \\
\hline $\mathrm{TI}$ & 26 & $2.2(2.8)$ & $\mathrm{I}, 0$ \\
\hline T6 & 24 & $1.8(2.1)$ & $\mathrm{I}, 0$ \\
\hline TI2 & II & I.7 (I.6) & 2,0 \\
\hline \multicolumn{4}{|l|}{ Vaginal itching } \\
\hline T0 & 26 & $2.1(2.8)$ & 1,0 \\
\hline TI & 26 & $\mathrm{I} .5(2.4)$ & 0,0 \\
\hline T6 & 24 & I.2 (2.0) & 0,0 \\
\hline TI2 & 11 & $1.5(2.2)$ & 0,0 \\
\hline \multicolumn{4}{|l|}{ Vaginal dryness } \\
\hline T0 & 26 & $5.5(3.6)$ & 6,0 \\
\hline TI & 26 & $3.7(3.5)$ & 3,0 \\
\hline T6 & 24 & $3.5(2.5)$ & 3,0 \\
\hline TI2 & II & $2.4(3.1)$ & $\mathrm{I}, 0$ \\
\hline \multicolumn{4}{|c|}{$\begin{array}{l}\text { Dyspareunia: Pain only at } \\
\text { sexual entry }\end{array}$} \\
\hline T0 & 26 & $6.3(3.5)$ & 8,0 \\
\hline $\mathrm{TI}$ & 26 & $4.4(3.7)$ & 4,0 \\
\hline T6 & 24 & $4.9(3.4)$ & 3,0 \\
\hline $\mathrm{T} 12$ & II & $3.3(3.1)$ & 3,5 \\
\hline \multicolumn{4}{|c|}{$\begin{array}{l}\text { Dyspareunia: Deep pain during } \\
\text { thrusting }\end{array}$} \\
\hline T0 & 26 & $5.2(3.6)$ & 4,0 \\
\hline TI & 26 & $4.2(4.0)$ & 4,0 \\
\hline T6 & 24 & $4.1(3.5)$ & 3,5 \\
\hline TI2 & II & $2.8(2.8)$ & 2,5 \\
\hline \multicolumn{4}{|l|}{ Dysuria } \\
\hline T0 & 26 & I.0 (I.8) & 0,0 \\
\hline $\mathrm{TI}$ & 26 & $0.4(1.1)$ & 0,0 \\
\hline T6 & 24 & $0.3(0.7)$ & 0,0 \\
\hline TI2 & 11 & $0.5(1.8)$ & 0,0 \\
\hline \multicolumn{4}{|l|}{ Total VAS score } \\
\hline T0 & 26 & $22.6(14.4)$ & 23,0 \\
\hline $\mathrm{TI}$ & 26 & $14.2(13.6)$ & $\mathrm{II}, 0$ \\
\hline $\mathrm{T} 6$ & 24 & $14.5(10.8)$ & 13,0 \\
\hline $\mathrm{T} 12$ & II & $11.2(9.2)$ & 5,0 \\
\hline
\end{tabular}

Notes: ${ }^{\$} \mathrm{~N}=26$ patients surveyed at least at time point T0-TI were included in the analysis "Total VAS score is the sum of the previous categories at each timepoint.

( $P=0.042$ ). At 6 months post-treatment, the median score showed an increase with respect to pre-treatment to 25.5 (mean=25.3; $\mathrm{SD}=10.6$ ) with $23 \%$ not significant improvement $(P=0.18)$. Considering the small sample size collected at T12, our results might suggest a further improvement at 12 months post-treatment with a median FSFI score of 32.9 (mean=30.8; $\mathrm{SD}=4.6)$ with $58 \%$ of improvement $(P=0.008)$, but more surveys at this timepoint are required.

\section{Discussion}

Genitourinary syndrome (GS) of menopause, previously known as vulvovaginal atrophy (VVA), is a high prevalence disease and its incidence is expected to increase together with the survival age. It has been estimated that, in the next 20 years, the menopause period will reach almost half of a woman's life. ${ }^{4}$ Indeed, the GS might also occur in premenopausal state under conditions of hypoestrogenism: post-partum period, after oophorectomy, radiotherapy, chemotherapy, or during pill and drugs intake, as well as after recurrent infections, and affects more than $20 \%$ of premenopausal women. ${ }^{2}$ That is the reason why we decided to include both post- and premenopausal women, the latest presenting with a history of prolonged pill consumption and/or recurrent, persistent vulvovaginal candidiasis.

Systemic estrogen therapy is not indicated for GS in menopause because it offers fewer benefits with respect to the side-effects, such as a slight increased risk of heart attack, stroke, breast cancer, and blood clots. ${ }^{10}$ This is why, when only vaginal symptoms are present, the vaginal therapy is the first treatment step recommended. ${ }^{11}$ Study results about local estrogen benefits are controversial, especially in oncological patients, ${ }^{12}$ although most studies show a significant improvement vs placebo. However not all patients solve their symptoms, and other therapies have been introduced: estrogen receptor modulators (ie, ospemifene) mostly effective for urinary symptoms, intravaginal dehydroepiandrosterone (DHEA; ie, prasterone), as well as local moisturizers and lubricants. ${ }^{8,9}$ Indeed topical, daily, long therapy is not very appreciated by all women and new, innovative strategies are required.

Laser therapy has been proposed with promising results, but it requires high cost devices that need long training times before being administered. Moreover, last year the FDA published a warning to discourage the use of laser devices in GS because of the high complications reported. ${ }^{16}$

Free hyaluronic acid is characterized by biostimulation properties. ${ }^{18-28}$ Its action realizes in the dermic layer, near to fibroblastic cells, promoting the epidermal 
Visual Analogic Scale by Timeline

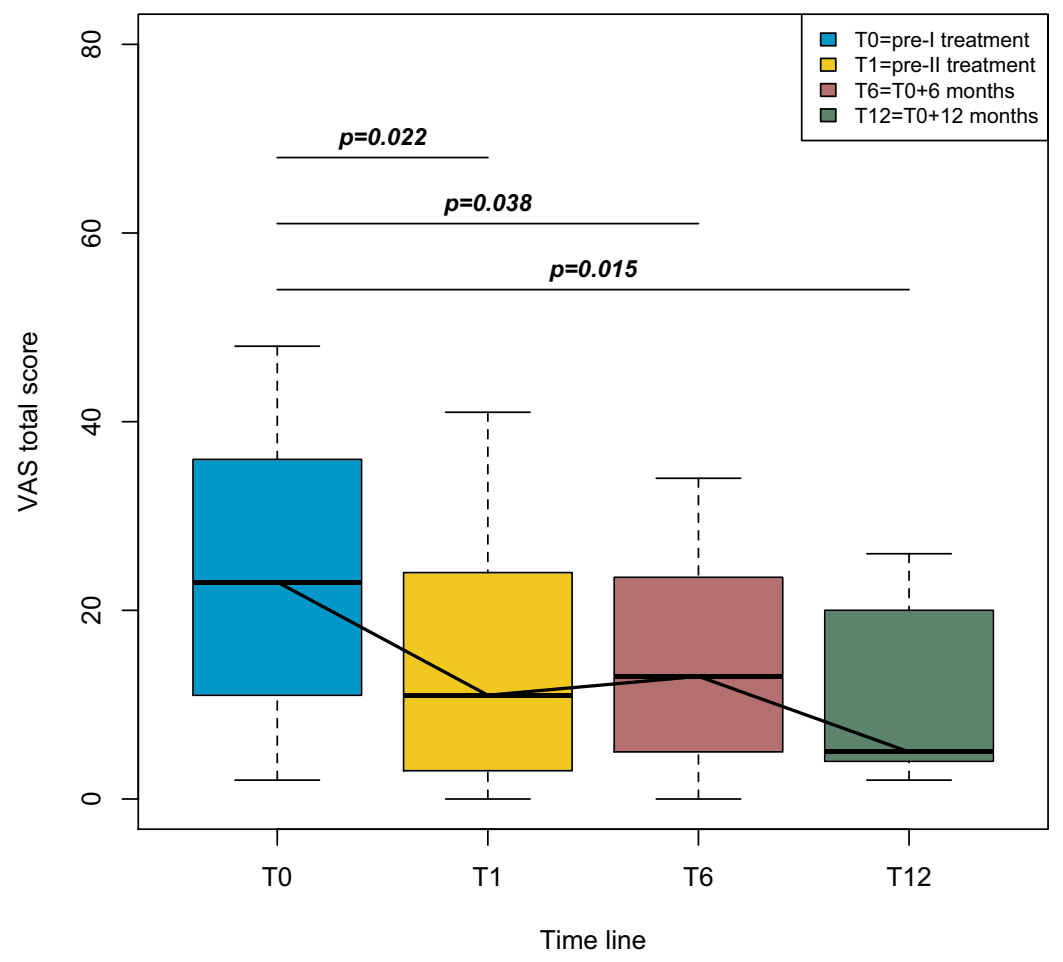

Figure 3 Boxplot of the Visual Analogic Scale across timepoint T0-TI2. The comparison across timepoints has been assessed using Wilcoxon Test, $P<0.05$.

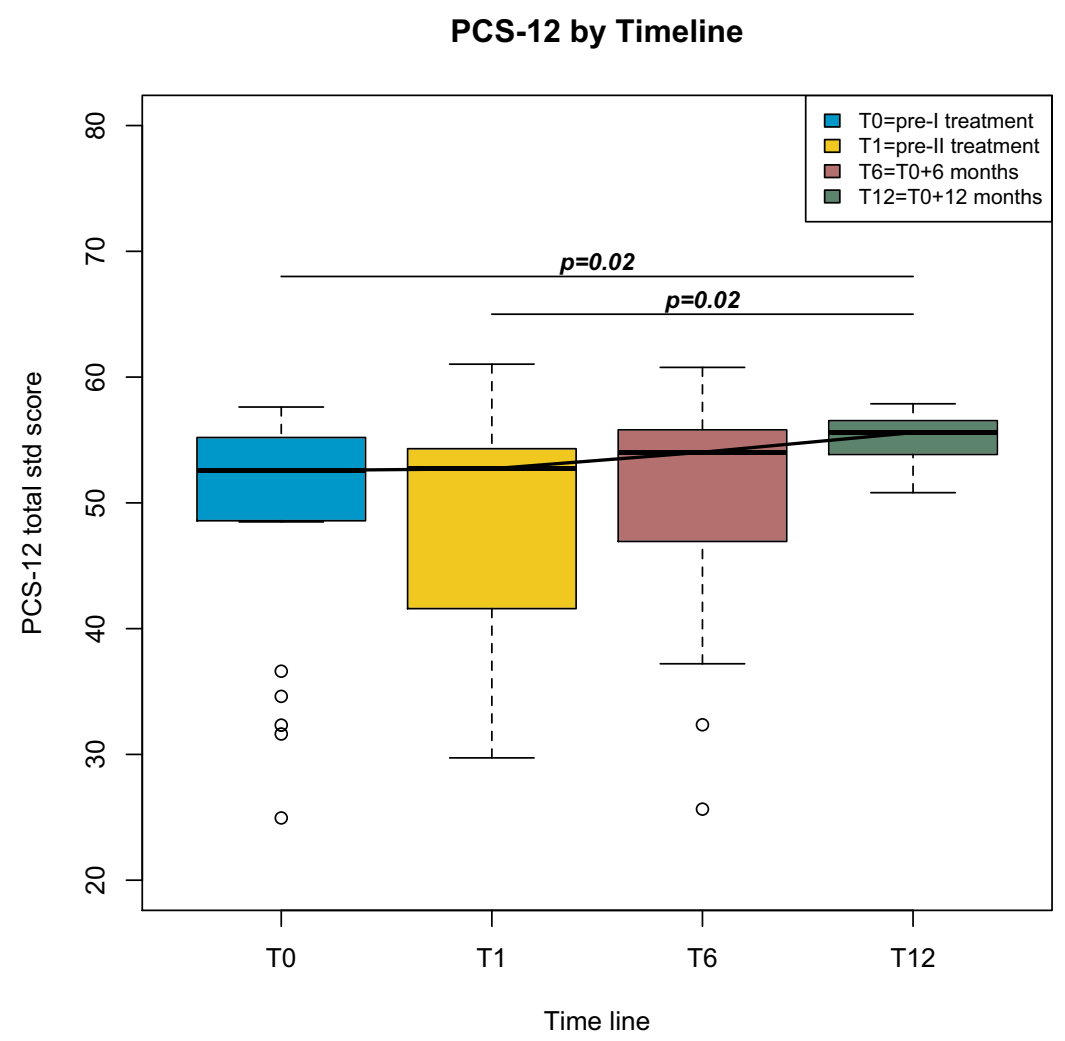

Figure 4 Boxplot of total PCS-12 score across timepoint T0-TI2. The total PCSI 2 has been standardized using a sample of American women according to the guideline [ref]. The comparison across timepoints has been assessed using Wilcoxon Test, $P<0.05$. 
MCS-12 by Timeline

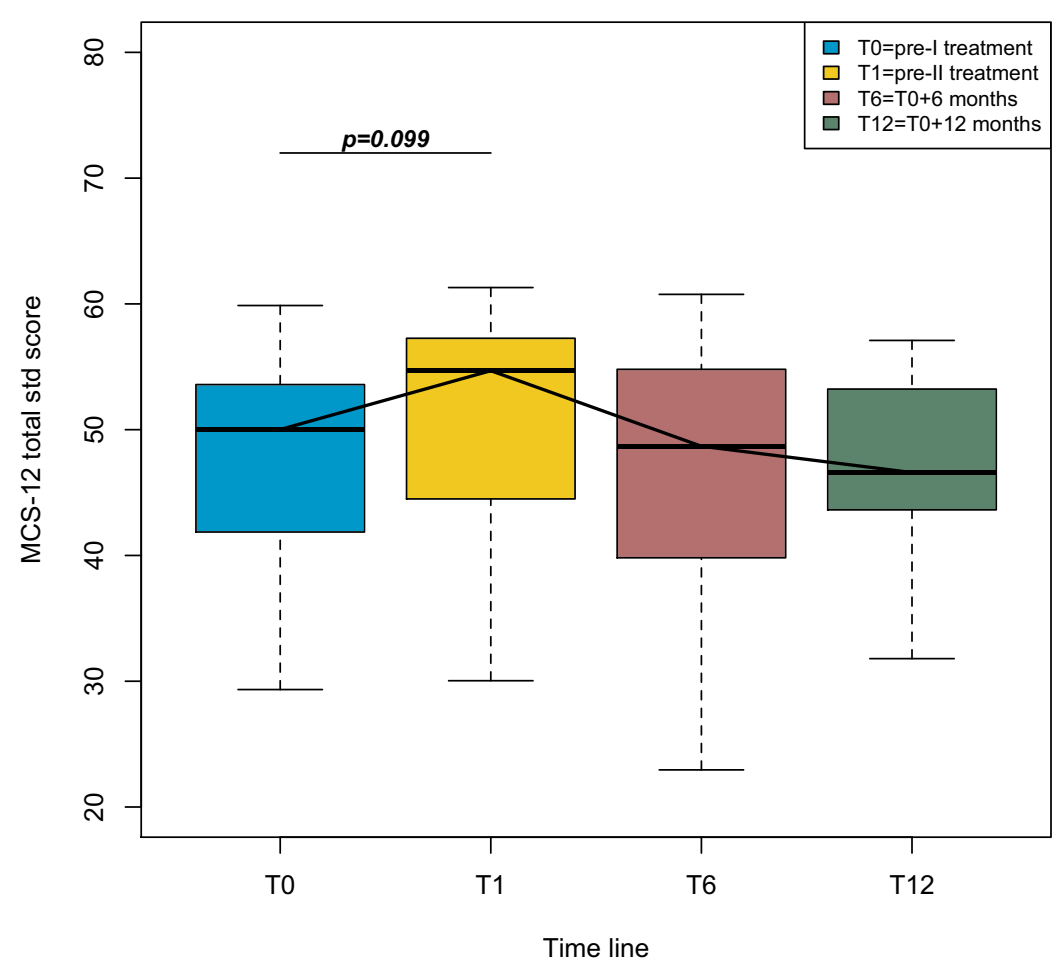

Figure 5 Boxplot of total MCS-12 score across timepoint T0-TI2. The total MCSI 2 has been standardized using a sample of American women according to the guideline [ref]. The comparison across timepoints has been assessed using Wilcoxon Test, $P<0.05$.

keratinocyte proliferation too. Its stereometric large volume does not allow it to cross the intact skin, and only injections can deposit HA in the correct site.

The few published histopathological examinations show evident tissue alterations in vulvar-vaginal atrophic tissue ${ }^{6,7}$ that can be repaired by the HA actions. Particularly we chose a specific hyaluronan hybrid, thermal stabilized (HCC), with low viscosity and optimal tissue diffusion, with two molecular weights that are involved in several and different actions: tissue hydration, fibroblast ${ }^{19,-21-25}$ and keratinocytes activation ${ }^{26,27}$, antioxidant, ${ }^{28}$ and antiinflammatory effects. ${ }^{34}$ Finally, HCC may recruit and differentiate stem cells in adipocytes at the subdermal fat compartment improving fat tissue renewal. ${ }^{35}$

Our experience is the first one using HCC only treatments at genital area in patients affected by GS with predominant vaginal vestibular atrophy. Diagnosis of GS is clinical and performed through an accurate anamnesis and a gynecological exam. Since GS shows different characteristics with respect to the damaged site (bladder, vaginal mucosa, and/or the vestibular, mainly at the posterior site), often accompanied by various degrees of pelvic floor muscles hyper-tone, the selection of the patients is crucially important. In our experience, we treated patients who presented most symptoms at the introitus conditioning discomfort daily and during intercourse.

The benefits from HCC injections have been estimated subjectively by observers through pictures and gynecological exam but, in this paper, we report only data that can objectively evidence the symptoms improvements through a self-evaluation survey, as well as the quality of mental and physical condition before the second treatment at 6 and 12 months after both treatments. The significant decreased median VAS score from 23.0 pre-treatment to 5.0 at 6 months and at 12 months $(P=0.015)$ and the patients' improvement in FSFI survey from median score 20.8 pre-treatment to 28.3 at 6 months $(P=0.18)$ and to 32.9 at 12 months $\left(P_{\mathrm{T} 6-\mathrm{T} 12}=0.023 ; P_{\mathrm{T} 0-\mathrm{T} 12}=0.008\right)$ suggests that HA injections are effective. The mental and physical status assessed by SF12 showed no statistically significant differences, but a slight improvement for physical scores, undoubtedly also for the necessity to increase study population but also because the symptom reported by the patients, such as dyspareunia, vaginal burning, itching, and dryness are annoying symptoms that did not much interfere with the physical activities explored by the 


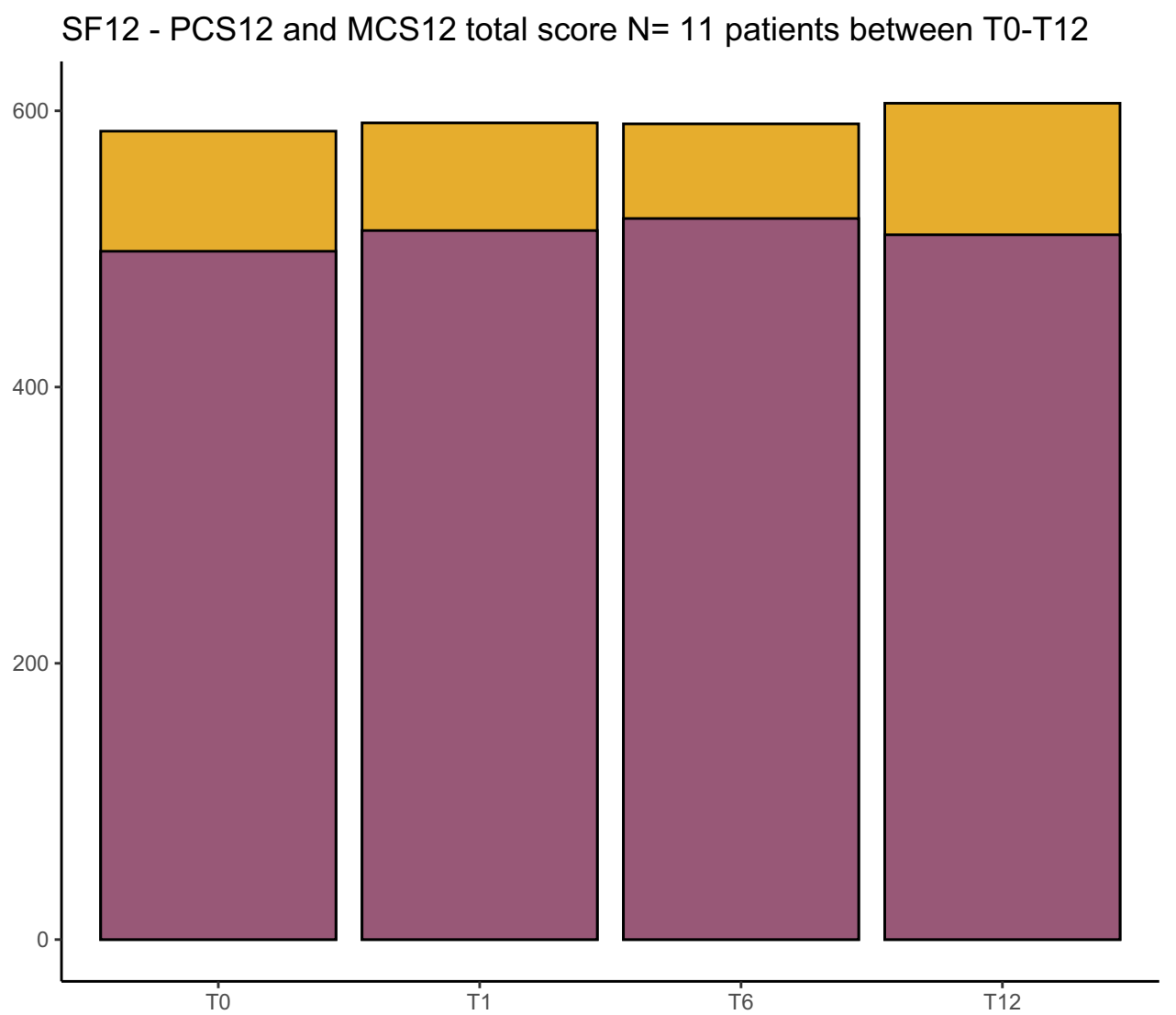

Figure 6 Cumulative total standardized PCSI2 and MCSI2 score for the entire sample at each timepoint. The comparison across timepoints has been assessed using Wilcoxon Test, $P<0.05$

physical domain included in the SF12 survey. The variability and the lack of improvement observed in analyzing the mental score assessment evidences the GS complexity and the need to involve other specialist doctors as a psychotherapist figure during the treatment. In fact, some symptoms, such as dyspareunia and pain during penetration, cause negative consequences on personal and couples life, ignored for a long time.

Mostly, our preliminary data stressed the importance of the safety of using HA in genital area: no complication or side-effects have been reported. The secondary aim was to highlight the benefit that has been reached, justifying the continuation of this clinical practice.

Dry needling has been shown to improve pain symptoms,${ }^{36}$ and this aspect should be considered in results evaluation, in our experience a limited number of injections have been executed during each treatment with a low clinical impact.

The limitation of our experience is the small sample size and the lack of a histopathological tissue collection.
About the first point, our current experience is increasing in order to be able to obtain more information that will allow our future investigation to stratify several sub-groups of women, ie, comparing pre- and postmenopausal women, women who received previous hormonal treatment vs no hormonal treatment or women with VVA associated to comorbidities such as vaginal scar and other condition. But the most important target will be the comparison of HA to local estrogen, that is the first therapeutic step proposed, even if we believe that the association of more strategies will be the most effective approach. About the second limitation, we have observed that also all the published studies on vaginal laser treatment have evaluated the clinical response through self-filled out questionnaires and we believe that some vaginal parameters under investigation $(\mathrm{pH}$ or maturation index) do not represent the best indicator of woman health and of her response to a treatment. 


\section{FSFI by Timeline}

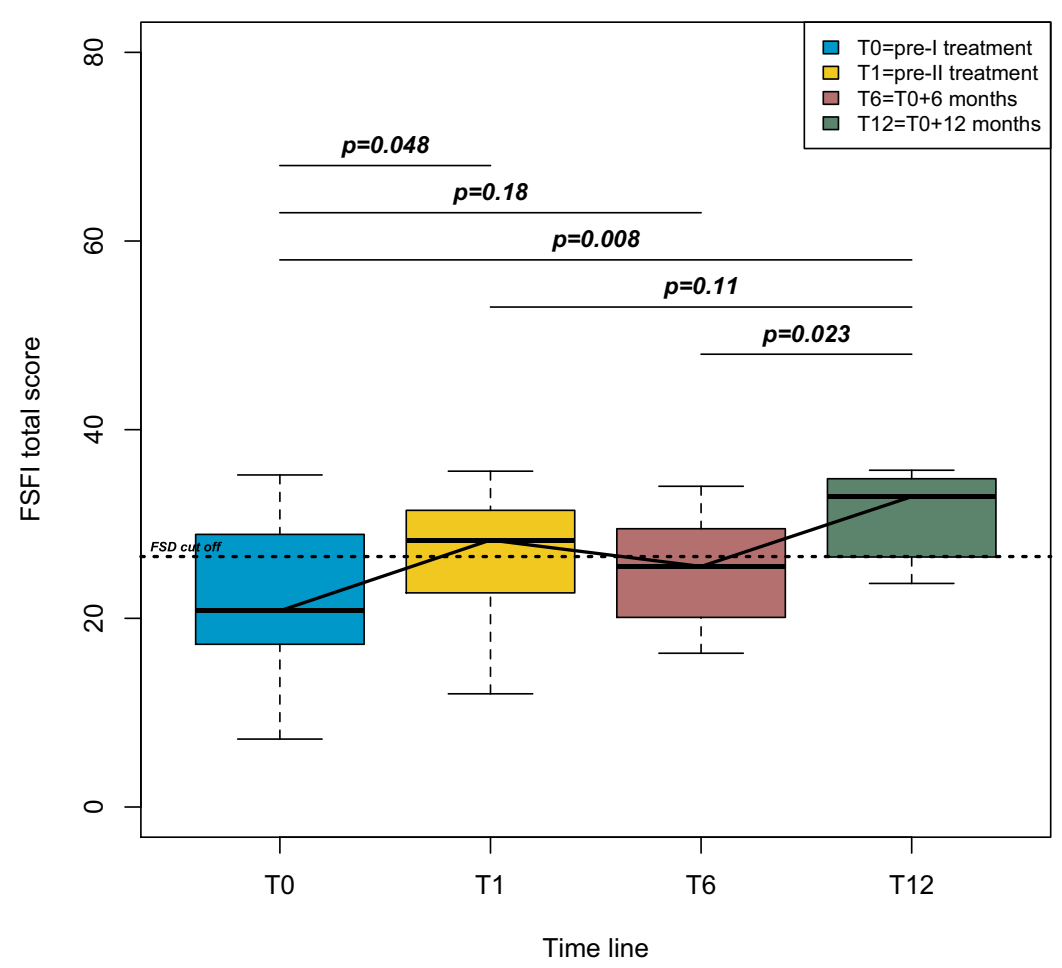

Figure 7 Boxplot of Female Sexual Function Index (FSFI) across timepoint T0-TI2. The dotted line indicates the Female Sexual Dysfunction (FSD) cut off. The comparison across timepoints has been assessed using Wilcoxon Test, $P<0.05$.

Although HA is currently used in genital area worldwide, this is the first experience published on HCC alone injection, where each patient has been followed up at the end of the 12 months and deeply investigated through 178 questions about clinical changes after treatments and the impact on general and sexual life.

Undoubtedly, more comparative studies with standardized endpoints are necessary to formulate a correct therapy according to the patient needs and degree of disease.

\section{Conclusion}

Vestibular HCC injection is an office, fast, not expensive, reproducible procedure. It is safe and effective in improving the life of women affected by vestibular atrophy and it may be proposed as one step of several treatments used for the complex GS. Thanks to its pharmacodynamic properties and safety, HCC could also be proposed to oncological women, who cannot take estrogenic drugs when affected by some hormone-sensible cancers. Our future efforts will be focused on extending the sampled population to confirm our findings and the application of this clinical procedure of bio-stimulation also to the vaginal mucosae.

\section{Acknowledgment}

We acknowledge Dr Michela Traglia for the statistical suggestions and scientific discussion.

\section{Disclosure}

GB is an employee of IBSA Farmaceutici Italia Srl and reports no other potential conflicts of interest for this work. The other authors declare that they have no conflicts of interest.

\section{References}

1. Portman DJ, Gass ML. Vulvovaginal atrophy terminology consensus conference panel. Maturitas. 2014;79(3):349-354. doi:10.1016/j. maturitas.2014.07.013

2. Mac Bride MB, Rhodes DJ, Shuster LT. Vulvovaginal atrophy. Mayo Clinic Proceedings. 2010;85:87-94. doi:10.4065/mcp.2009.0413

3. Kim HK, Kang SY, Chung YJ, Kim JH, Kim MR. The recent review of the genitourinary syndrome of menopause. J Menopausal Med. 2015;21(2):65-71. doi:10.6118/jmm.2015.21.2.65

4. Kagan R, Kellogg-Spadt S, Parish SJ. Practical treatment considerations in the management of genitourinary syndrome of menopause. Drugs Aging. 2019;36(10):897-908.

5. Akopians AL, Rapkin AJ. Vulvodynia: the role of inflammation in the etiology of localized provoked pain of the vulvar vestibule (vestibulodynia). Semin Reprod Med. 2015;33(4):239-245. doi:10.1055/ s-0035-1554919 
6. Fadare O. Vaginal stromal sclerosis: a distinctive stromal change associated with vaginal atrophy. Int $J$ Gynecol Path. 2011;30:295-300. doi:10.1097/PGP.0b013e3182005356

7. Salvatore S, Leoni Roberti Maggiore U, Athanasiou S, et al. Histological study on the effects of microablastive fractional CO2 laser on atrophic vaginal tissue: an ex vivo study. Menopause. 2015;22(8):845-849. doi:10.1097/GME.0000000000000 401

8. Di Donato V, Schiavi MC, Iacobelli V, et al. Ospemifene for the treatment of vulvar and vaginal atrophy: A meta-analysis of randomized trials. Part I: evaluation of efficacy. Maturitas. 2019;121:86-92.

9. Schiavi MC, Di Pinto A, Sciuga V, et al. Prevention of recurrent lower urinary tract infections in postmenopausal women with genitourinary syndrome: outcome after 6 months of treatment with ospemifene. Gynecol Endocrinol. 2018;34(2):140-143. doi:10.1080/ 09513590.2017 .1370645

10. Gandhi J, Chen A, Dagur G, et al. Genitourinary syndrome of menopause: an overview of clinical manifestations, pathophysiology, etiology, evaluation, and management. Am J Obstet Gynecol. 2016;215:704. doi:10.1016/j.ajog.2016.07.045

11. Biehl C, Plotsker O, Mirkin S. A systematic review of the efficacy and safety of vaginal estrogen products for the treatment of genitourinary syndrome of menopause. Menopause. 2019;26(4):431-453. doi:10.1097/GME.0000000000001221

12. Mitchell CM, Reed SD, Diem S, et al. Efficacy of vaginal estradiol or vaginal moisturizer vs placebo for treating postmenopausal vulvovaginal symptoms: a randomized clinical trial. JAMA Intern Med. 2018;178 (5):681-690. doi:10.1001/jamainternmed.2018.0116

13. Pitsouni E, Grigoriadis T, Falagas ME, Salvatore S, Athanasiou S. Laser therapy for the genitourinary syndrome of menopause. A systematic review and meta-analysis. Maturitas. 2017;103:78. doi:10.1016/j.maturitas.2017.06.029

14. Qureshi AA. Nonsurgical vulvovaginal rejuvenation with radiofrequency and laser devices: a literature review and comprehensive update for aesthetic surgeons. Aesthetic Surgery J. 2017;1-10.

15. Gordon C, Gonzales S, Krychman ML. Rethinking the techno vagina: a case series of patient complications following vaginal laser treatment for atrophy. Menopause. 2019;26(4):423-427.

16. FDA; 2018. Available from: https:/www.fda.gov/medicaldevices/ safety/alertsandnotices/ucm615013.html

17. Fakhari A, Berkland C. Applications and emerging trends of hyaluronic acid in tissue engineering, as a dermal filler and in osteoarthritis treatment. Acta Biomater. 2013;9(7):7081-7092. doi:10.1016/j. actbio.2013.03.005

18. Keen MA. Hyaluronic acid in dermatology. Skin Med. 2017;15 (6):441-448

19. Baggi GF, Prodi G. Effect of hyaluronic acid on skin lesions produced by staphylococci. Proc Soc Exp Biol Med. 1954;86 (3):461-464. doi:10.3181/00379727-86-21133

20. Vigetti D, Karousou E, Viola M, Deleonibus S, De Luca G, Passi A. Hyaluronan: biosynthesis and signaling. Biochim Biophys Acta. 2014;1840(8):2452-2459. doi:10.1016/j.bbagen.2014.02.001

21. Dicker KT, Gurski LA, Pradhan-Bhatt S, Witt RL, Farach-Carson MC, Jia X. Hyaluronan: a simple polysaccharide with diverse biological functions. Acta Biomater. 2014;10(4):1558-1570. doi:10.1016/j. actbio.2013.12.019

22. Hong L, Shen M, Fang J, et al. Hyaluronic acid (HA)-based hydrogels for full-thickness wound repairing and skin regeneration. J Mater Sci Mater Med. 2018;29(9):150. doi:10.1007/s10856-0186158-x
23. Hiramoto K, Kobayashi H, Yamate Y, Ishii M, Sato EF. Intercellular pathway through hyaluronic acid in UVB-induced inflammation. Exp Dermatol. 2012;21(12):911-914. doi:10.1111/exd.12032

24. Stern R, Maibach HI. Hyaluronan in skin: aspects of aging and its pharmacologic modulation. Clin Dermatol. 2008;26(2):106-122. doi:10.1016/j.clindermatol.2007.09.013

25. Bukhari SNA, Roswandi NL, Waqas M, et al. Hyaluronic acid, a promising skin rejuvenating biomedicine: A review of recent updates and pre-clinical and clinical investigations on cosmetic and nutricosmetic effects. Int $J$ Biol Macromol. 2018;120(PtB): 1682-1695. doi:10.1016/j.ijbiomac.2018.09.188

26. Kage M, Tokudome Y, Matsunaga Y, Hariya T, Hashimoto F. Effect of hyaluronan tetrasaccharides on epidermal differentiation in normal human epidermal keratinocytes. Int $J$ Cosmet Sci. 2014;36 (1):109-115. doi:10.1111/ics.12105

27. Symonette CJ, Kaur Mann A, Tan XC, et al. Hyaluronanphosphatidylethanolamine polymers form pericellular coats on keratinocytes and promote basal keratinocyte proliferation. Biomed Res Int. 2014;2014:727459. doi:10.1155/2014/727459

28. Stellavato A, Pirozzi AVA, Donato S, et al. Positive effects against UV-A induced damage and oxidative stress on an in vitro cell model using a hyaluronic acid based formulation containing amino acids, vitamins, and minerals. Biomed Res Int. 2018;2018:8481243. doi:10.1155/2018/8481243

29. Aguilar P, Hersant B, SidAhmed-Mezi M, Bosc R, Vidal L, Meningaud JP. Novel technique of vulvo-vaginal rejuvenation by lipofilling and injection of combined platelet-rich-plasma and hyaluronic acid: a case-report. Springerplus. 2016;5(1):1184. doi:10.11 86/s40064-016-2840-y

30. Hersant B, SidAhmed-Mezi M, Belkacemi Y, et al. Efficacy of injecting platelet concentrate combined with hyaluronic acid for the treatment of vulvovaginal atrophy in postmenopausal women with history of breast cancer: a Phase 2 pilot study. Menopause. 2018;25 (10):1124-1130. doi:10.1097/GME.0000000000001122

31. McCormack HM, Horne DJ, Sheather S. Clinical applications of visual analogue scales: a critical review. Psychol Med. 1988;18:1007-1019. doi:10.1017/S0033291700009934

32. Ware J Jr, Kosinski M, Keller SD. A 12-item Short-Form Health Survey: construction of scales and preliminary tests of reliability and validity. Med Care. 1996;34:33-220. doi:10.1097/00005650-1996030 00-00003

33. Rosen R, Brown C, Heiman J, et al. The Female Sexual Function Index (FSFI): a multidimensional self-report instrument for the assessment of female sexual function. $J$ Sex Marital Ther. 2000;26:191-208. doi:10.1080/009262300278597

34. D'Agostino A, Maritato R, La Gatta A, et al. In vitro evaluation of novel hybrid cooperative complexes in a wound healing model: a step toward improved bioreparation. Int J Mol Sci. 2019;20(19):4727. doi:10.3390/ijms20194727

35. Stellavato A, La Noce M, Corsuto L, et al. Hybrid complexes of high and low molecular weight hyaluronans highly enhance hascs differentiation: implication for facial bioremodelling. Cell Physiol Biochem. 2017;44(3):1078-1092. doi:10.1159/000485414

36. Leggit JC. Musculoskeletal therapies: acupuncture, dry needling, cupping. FP Essent. 2018;470:27-31. 


\section{Publish your work in this journal}

Medical Devices: Evidence and Research is an international, peerreviewed, open access journal that focuses on the evidence, technology, research, and expert opinion supporting the use and application of medical devices in the diagnosis, monitoring, treatment and management of clinical conditions and physiological processes. The identification of novel devices and optimal use of existing devices which will lead to improved clinical outcomes and more effective patient management and safety is a key feature of the journal. The manuscript management system is completely online and includes a very quick and fair peer-review system. Visit http:// www.dovepress.com/testimonials.php to read real quotes from published authors. 